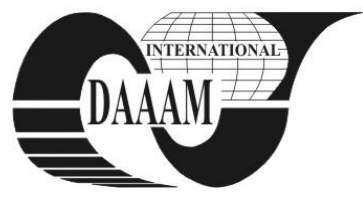

Annals of DAAAM for 2011 \& Proceedings of the 22nd International DAAAM Symposium, Volume 22, No. 1, ISSN 1726-9679 ISBN 978-3-901509-83-4, Editor B. Katalinic, Published by DAAAM International, Vienna, Austria, EU, 2011 Make Harmony between Technology and Nature, and Your Mind will Fly Free as a Bird Annals \& Proceedings of DAAAM International 2011

\title{
ACTIVE VIBRATIONS DAMPING OF BENDING FOR PRINTING ROLLER
}

\author{
VOICU, M[ariana] C[laudia]; LAMMEN, B[enno] \& SCHMIDT, R[einhard]
}

\begin{abstract}
The efficiency of printing or coating processes for paper products can be improved by increasing velocity of the web and roller width. These measures cause heating effects, deformation of the roller and streak print defects due to undesirable oscillations. An approved method like balancing of the rollers and maximizing the bending stiffness have come to technical limits.This paper describes the introduction of active vibration damping into a roller system by using piezoelectric actuators in the bearings. A feedback control strategy combined with a feed forward compensation of predictable disturbances has shown promising results in simulation and experiments
\end{abstract}

Key words: piezoelectric actuator, vibration, printing roller

\section{INTRODUCTION}

Roller systems in printing or coating machines tend to undesirable oscillations that affect the quality and the efficiency of the process. Approved methods like balancing of the rollers and maximizing the bending stiffness have come to technical limits. This paper describes an approach with piezoelectric actuators in the bearing of a roller. The roller system simulates the printing device of a flexographic printing machine. As shown in fig. 1, the ink is coated on the anilox roll (2) by means of a doctor blade (1) which transfers it onto the plate cylinder (3). Due to excitations caused by the canal impact or to the uneven surface of the printing plate when passing the nip in positions (5) and (6), oscillations can occur.

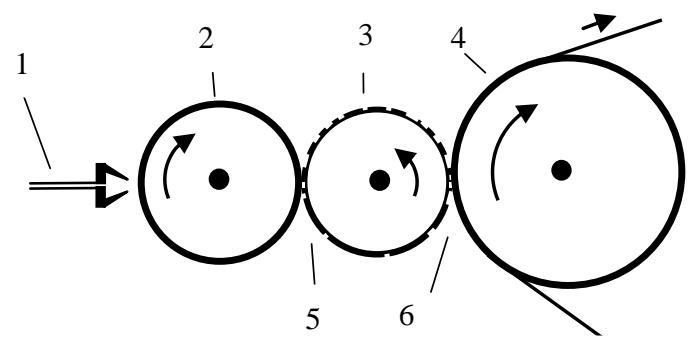

Fig. 1. Layout of a roller system in a flexographic printing machine

One method for further optimization is online monitoring and optimal adjustment of roller systems. In (Voicu et al., 2011) new sensor technologies for measuring the axial distribution of contact pressure along the nip are discussed. Another approach is to reduce the oscillation sensitivity especially of long rollers by applying active components such as piezoelectric actuators in the bearings or magnetic bearings in the center of the roller.

This paper describes an approach with piezoelectric actuators in the bearings of a roller introducing active counter forces to compensate undesired oscillations. The oscillations can be measured e.g. by means of strain gauges. After all, a mechatronic system including actuators, sensors and control strategies has to be designed, to reduce the oscillations in a of the roller system.

Active components for vibration damping have been introduced successfully also in grinding and milling machines (Ehmann et al.,2001; Ehmann et al., 2003).

\section{TEST BED}

A test bed simulating of a printing or coating machine was set up as shown in fig. 2. The test bed was designed with eigenfrequencies similar to an industrial plant. The roller in the middle (1) represents the plate cylinder. Strain gauges are applied in (2). As shown in the close-up view (taken without electrical drive and coupling) piezoelectric actuators (3) were integrated in the bearings in direction to the nip. The bearings (4) must be flexible to carry out small displacements without

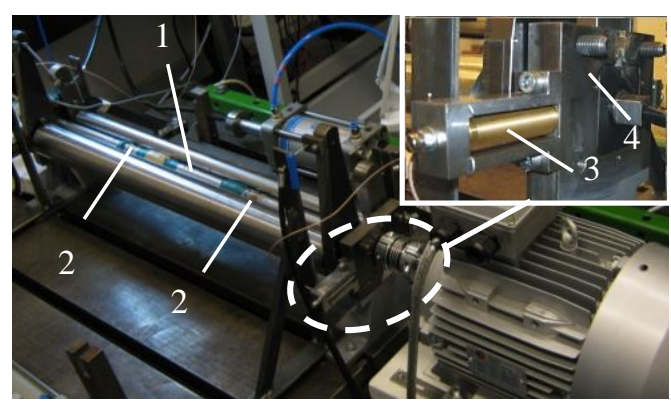

Fig. 2. Test bed

bearing shake. The strain of the plate cylinder is measured at two axial positions. The actuation the left and right bearing are controlled by two independent control loops.

Piezoelectric actuators are able to generate huge forces at high frequency with small displacements as required for this purpose.

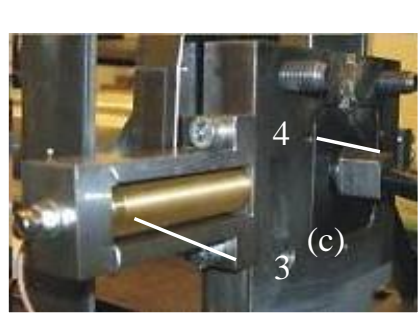

(b)

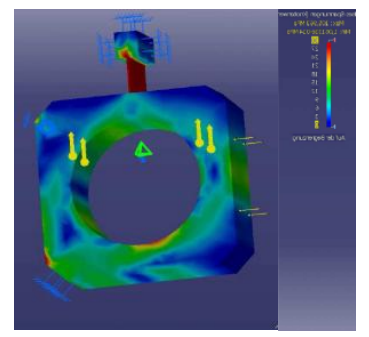

(c)
Fig. 3. (a) Small scale test set-up; (b) Active bearing; (c) Stress analysis of the flexible part of the bearing

Active bearing depicted in fig. 2 (without electrical drive and coupling) has a piezoelectric actuator (3) integrated in the 
bearings in the direction to the nip and preloaded using saucer spring packages (4) to compensate the tensile forces. The roller bearings must be flexible to carry out small displacements without bearing shake. Fig. 3 shows the stress analysis of the flexible part of the active bearing. The displacement of this part given by the piezoelectric actuator force is influenced by the thin elastic beam which is bonded with the body housing of the bearing.

\section{CONTROL STRUCTURE}

For measuring nip forces and vibrations of a roller, different technologies can be considered as discussed in (Voicu et al., 2011). Sensors and signal lines must be applied without mechanical impact on the system. Fig. 3 illustrates the over-all control structure. The bending vibrations of the roller are measured by strain gauges (1) at different axial positions on the roller (2). For transmitting these signals, a slip ring is mounted on the roller. A sensor (3) for measuring the rotational angle of the roller gives the absolute position of the strain gauges and the roller velocity. The signals are the feedback for the control unit (4) which activates the piezoelectric actuators (5) via high voltage direct current amplifiers (not depicted in fig. 3). In a first approach the forces of the actuators are applied in a radial direction to compensate excitations in the nip.

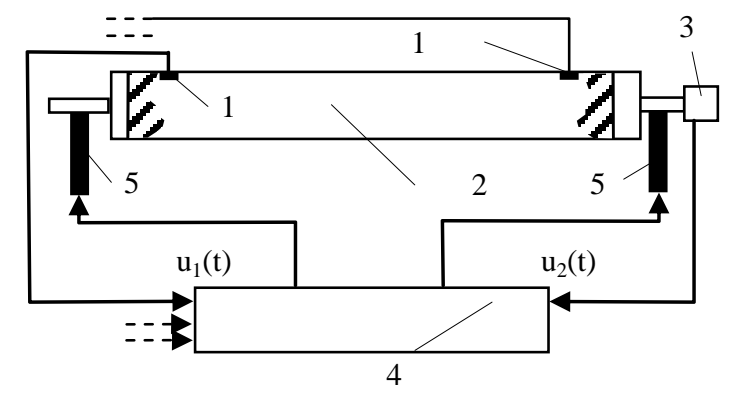

Fig. 4. Control structure

\section{EXPERIMENTAL RESULTS}

The control strategy, that is currently used, consists of a feed-forward control to compensate predictable periodic disturbances and a subsequent feedback control. The idea of the feed forward control is based on the assumption that most disturbances occur periodically with each rotation of the roller and can be predicted. The additional feedback control has to cope with the remaining control deviations.

The calculation of the feed forward control requires a runin-phase with the piezoelectric actuators. Passive profile rings are not yet used. The pilot control signal is calculated with a Least-Square Algorithm that minimizes the error by modifying coefficients of superimposed harmonic functions. In the current implementation the feedback control is designed as a simple PD-controller (Waller \& Schmidt 1989).

The test results in fig. 5 show the effect of the proposed control strategy. Two avoid problems with the signal transmission from a rotating system, the first measurements were done with non-rotating rollers. The oscillation of the plate cylinder was stimulated by a shaker fixed to the roller. Different periodic stimuli were evaluated.

The results in fig. 5 were taken with superimposed sinusoidal stimulation of $5 \mathrm{~Hz}$ and $15 \mathrm{~Hz}$. The control is activated after a time of $1.18 \mathrm{~s}$. It significantly reduces the oscillation of the roller. The results show, that the control strategy is promising and that the piezoelectric actuators are appropriate for active vibration damping.

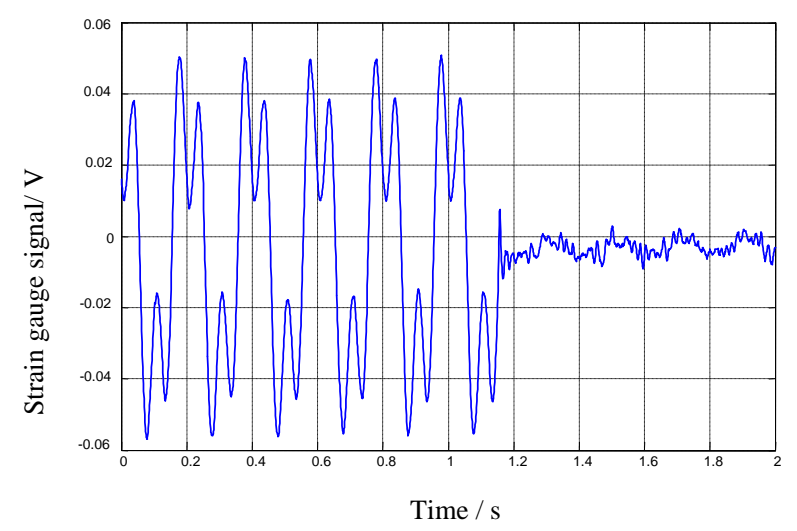

Fig. 5. Results of active vibration damping of a roller

\section{CONCLUSION}

To achieve high productivity and high quality demands in printing and coating processes the velocity of the web and the roller width can be increased. Long rollers tend to undesired oscillations at high web velocities. In this paper active vibration damping by means of piezoelectric actuators in the bearings of the rollers is proposed to reduce the oscillation sensitivity. Piezoelectric actuators are able to provide high forces at small displacements. The oscillations are measured with strain-gauge sensors. The mechanics of the roller system, the actuators and the sensors are combined with modern control techniques to a mechatronic overall-system. The design of the system is carried out based on a simulation model and on experiments with a test bed.

\section{ACKNOWLEDGEMENTS}

The authors wish to thank EFRE with the Ministry for Science and Culture of the land Lower Saxony for the granted sponsorship.

\section{REFERENCES}

Ehmann, C.; Nordmann, R. (2003). Comparison of Control Strategies for Active Vibration Control of Flexible Structures, Archives of Control Sciences, Vol. 13, 2003, No. 3, pp. 303-312

Ehmann, Ch.; Schönhoff, U.; Nordmann R. (2001): Aktive Schwingungstilgung bei Portalfräsmaschinen mit Hilfe integrierter Piezoaktoren, VDI Tagung Schwingungen in Anlagen und Maschinen, Veitshöchheim

Voicu, M.C.; Lammen, B.; Schmidt, R.; Hillbrand, H.-H.; Maniu, I. (2011): Messung der Anpressdrücke im Nip von Walzensystemen mit neuentwickelten piezoelektrischen Sensoren, VDI-Fachtagung Mechatronik, Dresden, pp. 1924

Voicu, M.C.; Hillbrand, H.-H.; Schmidt, R.; Lammen, B.; (2011): Design of an Active Vibration Control for a Roller System, $12^{\text {th }}$ International Workshop on Research or Education in Mechatronics, Kocaeli

Waller, H.; Schmidt, R (1989): Schwingungslehre für Ingenieure, Theorie, Simulation, Anwendungen, Wissenschaftsverlag, 1989 